\title{
Exploring the gap between what we say and what we do: Writing centres, 'safety', and 'risk' in higher education
}

\author{
Sherran Clarence iD \\ Centre for Postgraduate Studies, Rhodes University, Grahamstown, South Africa \\ E-mail: s.clarence@ru.ac.za
}

\begin{abstract}
Writing centres are a well-established aspect of student academic support in many universities around the world. As much as there is significant commonality in their espoused ways of working, and theoretical and ontological underpinnings, writing centres work in a diverse range of national and institutional contexts. At times, the pressures from their contexts - both ideological and practical - can work to shape the day-to-day nature of writing centre work that moves away from, rather than towards, their espoused ways of working. This gap between "theory" and "practice" in writing centres is the focus of this paper. The paper argues that acknowledging and characterising the nature of this gap in different writing centre contexts is vital, and needs to be taken on honestly and critically. This may better enable writing centres to act more consciously as a "critical conscience" in university spaces increasingly vulnerable to narrow, uncritical notions of 'safe' spaces for student development and growth.
\end{abstract}

Keywords: academic socialisation, academic literacies, contact zone, neo-liberalism

\section{Introduction}

Writing centres, as they are currently constructed, first opened their doors to students in the United States during the era of open admissions in the 1970s (Boquet 1999). Since then, their ethos and practices around developing student writing and writers in higher education have seen centres established at many universities in Canada, the United Kingdom and Ireland, continental Europe, and South Africa (Archer 2010, Boquet 1999). Most writing centres strive to be there primarily for student writers at postgraduate and undergraduate level to help them make sense of their academic writing, as many students experience the "rules" of writing at this level as a mystery or a code that needs to be cracked (Carter 2009, Shine Cain 2011). But increasingly, writing centre work has moved into the disciplines, with "Writing across the Curriculum" and "Writing across the Disciplines" initiatives well established in many national higher education sectors in which university-based writing centres exist. These initiatives, and other similar ones, aim to take the ethos and practice of writing centre work into disciplinary spaces where writing specialists work with academic lecturers to help them develop writing tasks, teaching and learning activities, and so on that make the seemingly "mysterious" ways 
of making knowledge and meaning through writing more knowable and achievable for more students (see, for example, Deane and O'Neill 2011, Paxton et al. 2008).

There is a growing body of writing centre research, internationally and in South Africa, that is increasingly committed to theorising writing centre practices, and to centering the role of writing centre work as academic development work within the university (see, for example, Archer and Richards 2011, Clarence and Dison 2017, Deane and O'Neill 2011). This research powerfully reflects a community of practice that is committed to social justice, diversity, and critical approaches to academic reading, writing, thinking, and knowing in higher education. However, the research only partially reflects this community's work, as not all writing centre practitioners, tutors, consultants, and directors publish in journals and books. Further, it should not be taken as a given that the ways in which we - and I include myself in this community as a writing development practitioner - theorise our practices are the ways we enact them with students and lecturers.

This paper contends that there is a gap between theory and practice that may be smaller in some university contexts than in others, especially in a higher education system as differentiated in terms of student intake, students' linguistic, home and school backgrounds, and physical and human resources as the South African system is. This gap - specifically, what writing centres do within it with the resources they have to create what they term "safe spaces" for student writers - is the concern of this paper. This paper particularly wants to probe the gap between what or who we say we are as writing centres, and what we do when we encounter students who need help with essays, and lecturers who need help with their students" "poor" writing. In other words, what exactly is this "safe space", and what are we both gaining and potentially losing in current enactments of "safety" in writing centre work?

The realities of practice may serve to strengthen or undermine theorised notions of ideal or preferential practices. This paper will argue that this gap and these realities are important to contextualise within the current dominant discourses shaping higher education, and to grapple with going forward as questions about knowledge, voice, and representation in higher education become more pressing. Writing centres have a crucial role to play as part of a critical conscience of sorts (see Boquet and Lerner 2008), particularly around the kinds of writing, reading, thinking, and speaking that are valued (and devalued) in higher education. But we need to begin with a careful critique of our own blindspots in this regard before we can offer this to the wider university community of which we are a part.

\section{South African writing centres within the context of academic development}

Writing centres in South Africa started opening their doors in the early 1990s at universities such as the University of Cape Town (UCT) and the University of the Western Cape (UWC), the former especially admitting black students who had been ill-served by the apartheid government's "Bantu education" strategy (Archer 2010, Leibowitz et al. 1997). In essence, these black students were under-prepared for the academic rigours of higher education because of their poorer school and home backgrounds. Although much research since the early 1990s has troubled any sense of these students as a homogenous group, the idea behind writing centres as part of a wider approach to academic development was to provide a space on campus to help these students in particular cope with the writing and reading demands placed on them. At this 
time, academic development as a field was undergoing significant shifts in its underpinning ontology, which influenced writing centres' development as well.

In South Africa, academic development as a field or movement can be traced back to the 1980s. Volbrecht and Boughey (2004) as well as Boughey and Niven (2012) trace three phases of academic development in South African higher education. The first phase was termed "academic support". The beginnings of this phase are traced back to the 1980s in the few historically-white universities that were, at that time, admitting small numbers of black students. These students, as mentioned, were deemed under-prepared for academic reading and writing demands, thus universities admitting them created various approaches to "skills development" for these students, such as foundational academic literacy courses in which students were taught to write essays, to think critically, and so on (Boughey and Niven 2012). These courses sat outside of the formal or mainstream curriculum. Boughey and Niven (2012) argue that many of the academics working with these students within these academic support spaces saw themselves as academic "activists" (646), challenging the apartheid regime's poor treatment of these students rather than challenging the social structures within universities themselves. Thus, the fact that most of the support was created and set aside for black students, and how this positioned them within the broader university as not quite belonging, was not initially questioned. The focus during this phase was mainly on helping these students to adjust to university learning and succeed through creative approaches to teaching and learning.

However, towards the end of apartheid in the early 1990s, this focus began to shift. As apartheid waned, more and more black students began to apply for university study, and universities that had previously only admitted white students from relatively privileged educational backgrounds and small numbers of black students were faced with the reality of working with much larger numbers of students who may have been under-prepared for university studies, and who could not be considered in any sense a homogenous group. Thus, academic support could no longer be housed in small, boutique spaces set aside for small groups of students; rather, academic development, as this second phase was termed, needed to be more widely located within the whole university (Boughey and Niven 2012). This shift in the teaching and research focus of academic development and support was accompanied by an ontological shift as well. Academic developers moved from seeing the challenge as being focused on the apartheid state and wider socio-political issues to seeing the need to challenge the university as a particular social, political, and cultural space in which black and white students and lecturers were differently positioned, supported, and enabled. Although apartheid officially ended in April 1994, the echoes of the legacy of inequality and division continued to be heard throughout universities, perhaps more so in those historically-white institutions that had long been protected by money and privilege.

Thus, during this phase, and the ensuing third phase of "institutional development", academic development work sought to bring the challenge to universities themselves. Research during this phase indicates a tension between using the platform of academic development work to question dominant structures of power within the universities and how they positioned academic support and development work, and evidencing successful practices that may have been less critical of universities themselves (and may have inadvertently reinforced homogenising characterisations of black students and literacy practices). Even though the 1990s saw funding made available for academic development and writing centres, the dominant models were couched in deficit discourses (Smit 2012) about black students especially, and 
academic development work was quite firmly located within add-on or side spaces adjacent to rather than within the formal or mainstream curriculum. Many of the foundation or extended curriculum offerings were taught by contract staff, rather than permanent staff, and needed to compete for funding annually to stay open. Hence, the result was likely to be tension between a desire to be critical of the very university that provided their livelihoods, and the desire to evidence value-added services so as to secure ongoing funding.

This tension resulted in a rather "schizophrenic" ontology for writing support and development within writing centres. Although only a small number of papers were published in the 1990s on writing centre work specifically, it evidences this tension. Papers by scholars such as Pam Nichols (2017) and Brenda Leibowitz et al. (1997) show these centres working from an activist underpinning, seeing writing in the academy as a social and socialised set of practices rather than a set of autonomous skills that are easily learned and transferred between contexts. This understanding of writing as a social practice stands in direct opposition to deficit discourses about writing in the university.

These deficit discourses - borne out of the academic support phase of the 1980s set up to "upskill" and develop poorer black students who needed help to join and succeed within academic disciplinary communities - serve to keep black students in the sphere of the underprepared and under-skilled. These discourses also serve to absolve the university of any responsibility to critique its own social, cultural, and political structures that welcome some students and alienate others. McKenna (2010) argues that these deficit discourses continue to privilege predominantly white, middle-class students - and thereby specific ways of knowing - who come to university from educational backgrounds more congruent with the ways of learning, writing, and thinking at university. By implication then, those who are alienated, both overtly and subtly, are black students who need to navigate a significant gap between their previous and current academic studies. These claims should not be taken to mean that students from privileged home and school backgrounds will always succeed, and that students from underprivileged backgrounds will not. Rather, the claim is that the underlying orientation to university literacy practices assumes a particular command of the medium of instruction, and familiarity with a range of text types that students from more well-resourced homes and schools are far more likely to have than students on the opposite end of this continuum.

Even though writing centres had and continue to have as their "bread and butter" the students from all backgrounds who struggle to traverse this gap - seen perhaps most clearly in their struggles with the writing demands in the disciplines - the writing centre community is critical of their positioning within remedial deficit discourses (Archer and Richards 2011). Rather, writing centres, in characterising their work and identity, maintain an activist stance underpinned by an ontology that sees writing as a social practice, and the social as fractured, multiple, and value-laden. This has resulted in work that challenges universities as homogenous sites of uncomplicated knowledge production. However, this paper suggests that there is a gap between the ways in which writing centres characterise themselves, and what they achieve and enact in practice.

Writing centre practitioners do not necessarily have the luxury of enacting such a critical praxis with student writers in the way they can envision this in writing about their practice. Student writers approach writing tutors or consultants with real and immediate struggles they need practical help with, such as finishing an essay or working out how to start a research project. Writing centres in South Africa tend to employ as consultants/tutors postgraduate students who 
are themselves still grappling with learning to write in particular ways (Mitoumba-Tindy 2017). Hence, everyone working in a writing centre, as either student or tutor, is a writer on a learning journey. There is therefore no firm claim to writing expertise. In fact, a key underpinning of writing centre practice is that consultants/tutors work as peers to students, assisting, advising, and guiding them with writing tasks but never instructing, telling or writing for the students (Gillam et al. 1994). This work, while largely underpinned by this ontology of writing as a social practice, and the social as needing to be approached critically (Archer 2010), can all too easily slip into deficit or remedial discourses, especially when writing tutors are confronted with students who are desperate, overwhelmed, and unable to write as yet at the level required of them. This creates a potential paradox: How do we work with students in ways that enable critical discussion about and grappling with knowledge production and scholarly identity (Archer and Richards 2011), when students (more pressingly) need to know how to construct basic paragraphs, for example, to complete an essay so that they at least have a chance at passing their course?

This is where the notion of 'safe spaces' comes into play. Writing centres the world over have long claimed that what they uniquely offer students within the university is a safe space (see Archer 2010, Mitoumba-Tindy 2017, Nichols 2017, among many others): a space where students are safe from judgement and grades, safe from negative language and feedback, and that is safe enough to use to explore new ideas, scholarly identities, and voice. Crucial is the latter - the notion of writing centres as a safe space within which emerging writers can figure out what they want to say without fearing judgement, failure or ridicule. However, this paper contends that the term "safe" has been used so often in relation to writing centre work that it may have become detached from more critical notions of safety, especially those related to the notion on the other side of that coin, risk. This is potentially problematic because it can deepen the divide between what writing centres are conceptually, and how they are able to work practically to achieve this conceptual role.

While acknowledging the significant value of writing centres as spaces safe from harsh judgement and negative feedback that too many students are exposed to, I would like to continue, in the remainder of this paper, to focus on exploring notions of 'safety' and 'risk' within the current writing centre context, and a wider social and political, higher education context. Specifically, I want to look at these ideas in relation to the concepts of 'academic socialisation' and 'academic literacies' advanced first by Mary Lea and Brian Street in 1998, and used in much writing centre work and academic development, especially in South Africa and the UK.

\section{3. "Safe spaces": What is "safe" about writing centre work?}

Writing centres refer to themselves as "safe spaces" (Archer and Richards 2011, MitoumbaTindy 2017, Nichols 2017), however, this term is used so often that it can mask differences between writing centre practitioners or researchers in what is meant by the notion of a "safe space' for student writers. In this section, I will unpack the different ways in which "safety" is understood in writing centre research and practice before moving on to discuss the notion of 'risk', and linking risk as well as a more critical notion of a 'safe space' to the expanded idea of a writing centre "contact zone".

The first and most often-mentioned understanding of a safe space is the absence of overt judgement on student writing. Writing centres do not assign marks to student work or indicate whether a piece of writing will pass or fail (Mitoumba-Tindy 2017). Writing centres are not in 
the business of telling students whether their work is "good" or not; rather, their work is to help students read and consider their writing through more critical eyes so that revisions and changes can be effected by the student, with a better understanding of what is required of them as writers and thinkers (Munje, Nanima and Clarence 2018). However, there is a flip-side to this notion of safety from judgement (in the form of marks or a passing grade, particularly). To help students see what is missing or under-considered in their writing so that they can revise it effectively, we invoke a set of (often invisible) standards of what counts as "good" academic writing (see Grimm 1999). What is a "good" introduction or a "complete" paragraph? Who sets this bar to which we all ascribe in our writing often without even considering why? There is always judgement when an editor or peer reads our writing because there is always a standard against which that writing is read and considered. However, this is not often made overt or discussed critically.

In a critical framing of a writing centre underpinned by the notion of academic literacies as sets of critical social practices, value-laden, and influenced by different forms of knowledge and knowing, (see Dison and Clarence 2017), these (invisible) standards or notions of "good" academic writing would be made visible through peer writing consultations. The peer writing consultant/tutor would not just explain what a complete introduction looks like, or what steps it should contain (i.e. background information on the topic, thesis statement, and so on). She may ask the student to reflect with her on whether the student thinks there could be different versions of a good introduction, taking into consideration the work an introduction needs to do in a particular text to orientate the reader. The student may then be invited, with guidance, to consider more critically what they are actually being asked to do, and how this does or does not tally with their prior understandings of writing, and with what they currently need and want to say in their writing.

However, in the mode of academic socialisation (Lea and Street 1998), where the focus is less on critiquing the social practices the writer is engaged in, and more on helping the writer meet the standard set for their text or writing, the peer tutor may invite the student to read their draft introduction aloud or in silence, and then ask them whether they think it is complete or not. The consultant/tutor then guides an exchange about the writing, focused on enabling the student to revise their draft to create a complete text along the lines of already-legitimated forms and rules. It is a given that before one can bend or break the rules, one has to know what these rules are and how they work. Hence, in Lea and Street's account of academic literacies, academic socialisation is a pre-cursor to academic literacies. However, much academic writing development work tends to stop at socialisation without pushing further into more critical territory that challenges and even changes the way we think about and teach academic writing (see Boquet and Lerner 2008). Although the socialisation-focused tutorial is undeniably going to help the student write a clearer or more adequate introduction, it may not actually lead as effectively to a change in the student's meta-level awareness of writing conventions, the development of their own authorial voice, or their standing as a legitimate knower in the university.

My contention in this case is that what we are making the space safe from is further student error. If we explain what good writing looks like, and use writing centre time to help students meet these standards - whether we are critical of the latter or not - we are limiting the risk of students getting it wrong in a further draft, and thereby not doing as well as they perhaps could in terms of the final grade. There are two risks here that we are mitigating: the first is the risk to the student, and the second is the risk to the writing centre itself. In the first instance, we are there for the students primarily, and we genuinely want them to feel more comfortable with 
academic writing and learning, and to do their best work. Thus, we want to maximise our limited time with them in consultations/tutorials to help them produce the best piece of writing possible. In the second instance, as so many writing centres continue to exist in relatively liminal spaces (Archer and Richards 2011), where their work is still too often misunderstood or under-valued in the overall university context (Shine Cain 2011), it is a risk to spend time talking to students about issues that go beyond their immediate assignment, and may perhaps develop the writer over the writing (cf. North 1984). Over the long-term, these critical conversations may have a far greater impact on students becoming legitimate, adaptable knowers and writers but they may not result in better writing in the immediate or short-term. If the student hands in poor work after claiming help from the writing centre, how are we to show our value and importance? Are we not inviting the risk of being further marginalised, and pushed back into remedial discourses?

There is a second main instance of safety connected to the first. This is an understanding of writing centres as a safe space in which to try out and develop an authorial "voice" (O'Sullivan and Cleary 2014). Here, the role of the writing centre is cast as creating conversations where student writers can "try on" different "voices" or ways of expressing ideas and making claims in their writing. However, this is again a risky option, especially for writing centres working in universities where the majority of students are from poorer home and school backgrounds, and are at greater risk of struggling with university writing demands due to a range of reasons linked to the incongruence of their prior learning and writing with what is required of them at university. When students who are struggling ask for assistance, conversations that are more expansive and less immediately-focused, that have them trying out different ways of expressing ideas, are risky. To create genuine spaces for error, feedback, and learning is to risk students turning in writing that does not immediately meet the lecturers' expectations or standards. And the judgement of the student may well be passed on to the writing centre, especially in a context where writing centres are seen as remedial, and there to fix poor student writing. Thus, writing centres mitigate this risk, consciously or unconsciously, by showing students how to write more effectively to the standards, thus socialising students into the dominant forms of writing at university without necessarily pushing further into taking a critical stance vis-à-vis these forms.

To what extent then are writing centres theorising their work framed by an academic literacies approach (see Lea and Street 1998) yet limiting their practice to less critical forms of academic socialisation? Is this gap really such a problem? I would argue that writing centres are, perhaps less consciously than they may realise, enacting "safer" forms of academic socialisation in practice more often than they enact a more critical, expansive, "risky" literacies approach, and that this could potentially be a significant problem. In 1996, Nancy Grimm argued that writing centres need to be careful to avoid becoming "handmaidens" to dominant discourses with the university that construct writing well as a discrete skill, ignorant of different disciplinary genres, discourses, and forms of knowledge-making. Volbrecht and Boughey (2004) further argue that academic development as a whole has moved away from its activist stance of the 1990s, and has become subsumed within dominant discourses of measurement, quality assurance, and management of expectations that have come with a neo-liberal approach to higher education over the last two decades or so. Taken together, these arguments represent a warning to writing centres: if we opt for the safer approaches to our work that socialise students into dominant modes and forms of academic writing to meet a tacit standard, we are risking subsumption into a discourse of measurement and performance that belies the activist, critical roots we are justifiably proud of. We risk subverting our role, for students and for the university, as a critical 
voice, questioning dominant discourses of "deficit" (Smit 2012) and "under-preparedness" that continue to cast students who "cannot write" as the problem rather than challenging what counts as "good academic writing" in the first place. We risk becoming a handmaiden (Grimm 1996) to dominant, narrow discourses of employability, skills development, and "relevance" that threaten the vibrancy of higher education as a space for the development of critical consciousness and critique, enacted through reading, writing, and thinking in new ways that question and challenge the status quo.

The current conversations around the decolonisation of higher education are not just for the disciplines, or for those with identifiable canons or knowledge bases. They are for all who work with students to help them express, refine, write about, and rewrite their thoughts, their learning, their place in the world. Writing centres have a critical role to play in these conversations, as they can play the role of consciously naïve outsider to the disciplinary knowledge and genres (Rai and Lillis 2011), asking crucial questions about what counts as knowledge as well as ways of expressing and knowing that knowledge. We can offer students and lecturers a space in which they can suspend what we already know about writing and knowledge, and see these elements of academia through fresher, more critical eyes. But we cannot do this and then continue to use our consultation time with students to only socialise them into "good" academic writing practices so as to mitigate the risks of students failing to do well, thereby threatening the writing centre's reputation and relevance in the process. We thus have to work more consciously on closing the gap between the ways in which we characterise our work in our research and writing, and the ways in which we actually work practically in engagements with students, peer tutors and consultants, and academic lecturers.

\section{Closing the gap through creating a "contact zone"}

In 1999, Mary Louise Pratt introduced the notion of learning or working in "contact zones" (1999: 584), where this concept is understood as a "social" space in which "cultures meet, clash and grapple with each other, often in contexts of highly asymmetrical relations of power". This idea is picked up by Thesen (2014: 3), writing about risk and development in postgraduate writing, who argues further that "the contact zone is the crucible in which we produce knowledge through writing". A crucible can be understood as a trial or ordeal that can shape or transform the person or entity enduring the process. In literature, crucibles are represented as transformative and challenging (consider, for example, Arthur Miller's eponymous play where the characters encounter trials or tests that change them during the process of being endured). This idea is at the heart of the way writing centres - aligned with critical, theoretically informed understandings of academic literacies and academic development - construct and enact their practice. Writing centres argue that learning to produce knowledge in the ways recognised as legitimate within the university is a challenging task that all students need assistance with. They acknowledge that students from poorer home and school backgrounds will likely need more assistance, probably over a longer period of time, than students from home and school backgrounds that are highly literate and well-resourced. But they push back against remediation and deficit discourses that uncritically cast poorer, less literate students as deficient, and needing "special" help to succeed at university study (Archer and Richards 2011).

As early as 1984, Stephen North famously argued that all student writers need readers to comment critically and constructively on their writing. Writing is about thinking, and thinking is a practice that evolves over time through engagement with texts, peers, lecturers, tutors, and 
so on. Thus, writing centres are actually there to engage with student writers about the ways in which they are reading, thinking, and writing about their coursework. But, in this contact zone, where student writers come to learn about how to construct and present knowledge in legitimate and powerful ways, how much space is really created for students' writing, reading, and thinking cultures to "meet, clash, and grapple" (Pratt 1999: 584) with those of the disciplines within the university? Do we in writing centres open up critical spaces for students to question received knowledge about what counts as the "right" kinds of writing and reading activity? Or, following Thesen (2014), do we rather act as a form of gatekeeper, managing students' choices about what to write and how to write it?

This is a crucial question, and one that is not fully considered in the day-to-day of writing centre practice. What we really want in writing centres, and writing across the disciplines in higher education, is an academic literacies approach to be enacted (Lea and Street 1998). But what we tend to invest time, money, and energy in through workshops, engagements with lecturers and students, and also research, is academic socialisation. This is perhaps not a hugely contentious claim when one considers the realities of working in increasingly diverse university contexts where the diversity is linguistic, socio-economic, and socio-cultural (see Council on Higher Education 2013). To paraphrase Carter (2009), we are there for the students and there for the university - we have a responsibility to the students who come to see us, and the lecturers and departments we work with, to help them rethink their approach to writing in ways that enable them to feel more able, confident, and knowledgeable when doing so. And we have to work with students who have been prepared for further education by their schooling in very different ways, in terms of the prior experiences of writing, reading, and thinking about knowledge and the world around them. This creates practical considerations that may be quite different from our more conceptual, theorised conceptions of who and what writing centres are, and how they can best work in university contexts.

There are perhaps, then, different kinds of contact zones implied here. In the first instance, there is the contact zone as conceptualised by Pratt (1999) and Thesen (2014), supported by critical research in writing centres (Archer and Richards 2011, Grimm 1999, Nichols 2017). This is a contact zone marked by productive struggles for meaning and representation of meaning, where the diverse knowledges and meanings students come to university with are incorporated into discussions about the new knowledge and meanings they are writing about, and are part of creating the latter rather than silenced or pushed aside as out-of-place or unhelpful. This contact zone is well represented in much of the critical work on writing centres and academic literacy development in higher education. But it may not always be realised quite as ideally in practice, the enactment of which is always messier and more complex than the conceptualisation of it. Students approach writing centres for a range of reasons, from wanting help with "fixing their grammar" to wanting to know if they are "on the right track" to just wanting to pass their assignment. Lecturers who send students to writing centres often do so because they (erroneously) separate skills from content, and see their role as managing the latter while writing centres teach the former.

The narrow, limited understanding of writing as a discrete skill denies the powerful and complex role of writing as a vehicle for learning, creating knowledge, and grappling with the worlds of meaning of which the disciplines are a part. Yet it is a powerful and dominant understanding of writing in higher education the world over because it is easier to understand writing as a skill that can be taught and learned in a straightforward "academic literacy" or "English for academic purposes" course. It is much more difficult to understand writing as a 
complex social practice that is imbued with tacit values that shape what counts as legitimate forms of writing, and what counts as a legitimate "voice" expressed through text. This understanding of writing calls for a more layered, nuanced, and lengthy teaching and learning process, one in which everyone in the university must play a part: lecturers, tutors, writing centres, academic development staff, and students.

Universities in the grip of neo-liberal approaches to higher education (Marginson 2015, Shore 2010) - where teaching is subordinate to research, and is poorly understood, funded, and supported - may well struggle with the more complex, layered, and lengthy approaches to developing student writers, with writing as a vehicle for this development rather than a discrete end-product of a task or examination. This is, I would argue, because the current dominant discourse in higher education values product over process. Lecturers are valued in terms of the papers they can actually publish, the students they graduate, and the evaluations that show that their courses and teaching meet the demands or expectations of the students (who are cast as customers or clients, rather than co-creators of knowledge). Exactly how the papers are conceptualised and written, and how the students are supervised or taught, is less of a concern than the visible outcomes that universities can then use to claim government subsidy, status and rankings, and so on (Butler-Adam 2015). In this product-oriented environment, much of the academic labour that shows research, teaching, learning, writing, and knowledge production to be social practices - imbued with legitimated values, norms, and so on - is less visible or even invisible. This makes it easier to construct and fund the development of writing as a skill rather than a practice, and students who "cannot write" as needing remediation rather than as novice "knowers" who need mentoring into a disciplinary community of practice from those who have specialist knowledge, skills, and dispositions.

This pervasive discourse of remediation that reduces knowledge-making and writing to skills rather than seeing them as complex practices that are learned over time through immersion in and critical engagement with specialists in the disciplines, supports a second, more limited notion of a contact zone; in this case, where highly asymmetrical power relations between those of the dominant culture (academia) and those from more marginal cultures (home, school, outside academia) are maintained rather than challenged such that the process of grappling with meanings is limited to forms of academic socialisation. By this, I mean that, rather than expanding the notion of the contact zone to enable a more meaningful, complex, and openended form of grappling between these two sets of cultures and their respective approaches to meaning-making, this limited notion of the contact zone is devoted to ensuring that students focus only on the meanings that have already been deemed legitimate. They are then socialised into the dominant writing, textual, and meaning-making practices of the disciplines without being encouraged or enabled to critique these or challenge them as part of their learning process. Although this happens perhaps unconsciously, and more often in the disciplines that form the centre of the university's academic life, those actors on the margins, such as learning and writing centres, and academic development units, are drawn in as well. We are there for the students and there for the university, as Carter (2009) argues. As such, we have to walk a tricky line between conceptualisations of our practice as being underpinned by a more critical notion of academic literacies, with our space a more expansive contact zone for student writers, and a more limited, "safer" practice that focuses on showing students how to write, read, and think in the already-legitimated ways of the disciplines. 


\section{Holding onto the critical in our own contact zones}

This paper closes by acknowledging that in South Africa, as in other contexts such as the United States and the United Kingdom, writing centres work within highly differentiated higher education systems. This differentiation comes, as a few examples, in the form of rural and urban universities, socio-economic and linguistically differentiated student populations, and a range of forms of financial and resource support from government and alumni. This range of real, often constraining contextual factors shapes the work writing centres feel able to do within the spaces they occupy, and these effects cannot be underestimated. That there is a gap between what writing centres would like to be and how they ideally want to work, and the ways in which they actually enact their practice, is not so contentious a claim to make. Yet it is important to acknowledge this gap, and work to substantiate the forms it takes so that we can work more consciously to close or at least bridge it where possible.

This gap between theory and practice in writing centres is important to acknowledge and characterise because the realities of day-to-day work with students, lecturers, and peer consultants/tutors can push it into the background. We may find ourselves becoming less able or willing to acknowledge the ways in which writing centre practice leans towards narrower notions of a 'safe space', and a less expansive enactment of the contact zone as uncritical academic socialisation. This is potentially dangerous as it makes writing centres vulnerable to being subsumed into a dominant culture of quality as "value for money" and as a form of perfection rather than quality as transformative (Harvey and Green 1993), which would require more critical and more risky approaches to writing centre work. Writing centres have long held an activist mentality about their work. Writing centre work across different national contexts and higher education systems has been constructed, since the 1970s at least, as critical of dominant discourses in higher education that seek to reduce complex processes of learning, claiming voice, and sharing and debating knowledge, to skills and issues of language competence (usually in English). This critique goes beyond individual universities, and locates these discourses and their roots within broader social and cultural structures that shape the environments between which universities and their students and staff move (e.g. home and school, and school and work).

To hold onto this stance, and the vital critical voice that writing centres can use within universities to continually challenge narrower notions of 'safety' and 'risk', writing centres need to acknowledge this gap. This is especially crucial now and into the near future, which is becoming increasingly uncertain and unsafe as governments and corporations become more resistant to critique and challenge. Within their own contexts and environments, writing centre directors, coordinators, and practitioners need to look critically at the ways in which their practice and their conceptual accounts of their work and vision do not fully align, and why this is so. Contextual limitations and realities notwithstanding, writing centres in the $21^{\text {st }}$ century have a crucial role to play as a critical consciousness within the university. To this end, we must defend more expansive notions of 'risk' and 'voice' within our work, inside our centres as "contact zones", and within the wider university community. Moving forward into an uncertain future requires us to hold this space, and push back against constraints that would limit this: the long-term gains for both student writers and the universities we serve demand nothing less. 


\section{References}

Archer, A. 2010. Challenges and potentials for Writing Centres in South African tertiary institutions. South African Journal of Higher Education 24(4): 495-510.

Archer, A. and R. Richards. (eds.) 2011. Changing spaces: Writing centres and access to higher education. Stellenbosch: SUNPress.

Boquet, E.H. 1999. "Our little secret": A history of writing centers, pre- to post-open admissions. College Composition and Communication 50(3): 463-482. https://doi.org/ $\underline{10.2307 / 358861}$

Boquet, E.H. and N. Lerner. 2008. After "The idea of a writing center". College English 71(2): 170-189.

Boughey, C. and P. Niven. 2012. The emergence of research in the South African academic development movement. Higher Education Research \& Development 31(5): 641-653. https://doi.org/10.1080/07294360.2012.712505

Butler-Adam, J. 2015. Financial reward for research output under the spotlight in South Africa. Available online: http://theconversation.com/financial-reward-for-research-output-under-thespotlight-in-south-africa-45567 (Accessed 18 July 2019).

Carter, S. 2009. The writing center paradox: Talk about legitimacy and the problem of institutional change. College Composition and Communication 61(1): 133-152.

Clarence, S. and L. Dison. (eds.) 2017. Writing centres in higher education: Working in and across the disciplines. Stellenbosch: SUNPress.

Council on Higher Education. 2013. A proposal for undergraduate curriculum reform in South Africa: The case for a flexible curriculum structure. Pretoria: Council on Higher Education.

Deane, M. and P. O’Neill. (eds.) 2011. Writing in the disciplines. London: Palgrave Macmillan.

Dison, L. and S. Clarence. 2017. Introduction. In S. Clarence and L. Dison (eds.) Writing centres in higher education: Working in and across the disciplines. Stellenbosch: SUNPress. pp. 5-16. https://doi.org/10.18820/9781928357551

Gillam, A., S. Callaway and K.H. Wikoff. 1994. The role of authority and the authority of roles in peer writing tutorials. Journal of Teaching Writing 12(2): 161-198.

Grimm, N.M. 1996. Rearticulating the work of the writing center. College Composition and Communication 47(4): 523-548. https://doi.org/10.2307/358600

Grimm, N.M. 1999. Good intentions: Writing center work for postmodern times. Portsmouth, NH: Boynton/Cook. 
Harvey, L. and D. Green. 1993. Defining quality. Assessment \& Evaluation in Higher Education 18(1): 9-34.

Lea, M.R. and B.V. Street. 1998. Student writing in higher education: An academic literacies approach. Studies in Higher Education 23(2): 157-172. https://doi.org/10.1080/0307507 $\underline{9812331380364}$

Leibowitz, B., K. Goodman, P. Hannon and A. Parkerson. 1997. The role of a writing centre in increasing access to academic discourse in a multilingual university. Teaching in Higher Education 2(1): 5-19. https://doi.org/10.1080/1356251970020101

Marginson, S. 2015. The Landscape of Higher Education Research 1965-2015 - Equality of Opportunity: The first fifty years. Keynote Address: SRHE $50^{\text {th }}$ Anniversary Colloquium (Valuing Research into Higher Education), 26 June 2015. Available online: https://www.srhe.ac.uk/downloads/SimonMarginsonKeynote.pdf (Accessed 18 July 2019).

McKenna, S. 2010. Cracking the code of academic literacy: An ideological task. In C. Hutchings and J. Garraway (eds.) Beyond the university gates: Provision of extended curriculum programmes in South Africa. Grahamstown: Rhodes University. pp. 8-15.

Mitoumba-Tindy, H. 2017. Working in the interspace between subject knowledge and academic literacies: Writing centres as a zone of proximal development. In S. Clarence and L. Dison (eds.) Writing centres in higher education: Working in and across the disciplines. Stellenbosch: SUNPress. pp. 67-80. https://doi.org/10.18820/9781928357551

Munje, P.N., R.D. Nanima and S. Clarence. 2018. The role of questioning in writing tutorials: A critical approach to student-centered learning in peer tutorials in higher education. Mentoring \& Tutoring: Partnership in Learning 26(3): 336-353. https://doi.org/10.1080/13611267. $\underline{2018.1511953}$

Nichols, P. 2017. 'Hopeful' directions for writing centres in South Africa: From safe spaces to transitional sites of articulating practice. Stellenbosch Papers in Linguistics Plus 53(1): 182-194. https://doi.org/10.5842/53-0-741

North, S.M. 1984. The idea of a writing center. College English 46(5): 433-446.

O'Sullivan, I. and L. Cleary. 2014. Peer-tutoring in academic writing: The infectious nature of engagement. Journal of Academic Writing 4(1): 52-65. https://doi.org/10.18552/joaw.v4i1.72

Paxton, M., E. Van Pletzen, A. Archer, M. Arend and C. Chihota. 2008. Writer's stance in disciplinary discourses: A developmental view. Southern African Linguistics and Applied Language Studies 26(1): 107-118. https://doi.org/10.2989/salals.2008.26.1.9.424

Pratt, M.L. 1999. Arts of the contact zone. In D. Bartholomae and A. Petrosky (eds.) Ways of reading: An anthropology for writers. New York: Bedford/St Martins. pp. 582-596.

Rai, L. and T.M. Lillis. 2011. A case study of a research-based collaboration around writing in social work. Across the Disciplines: A Journal of Language, Learning, and Academic Writing 8(3): 1-9. 
Shine Cain, K. 2011. From comfort zone to contact zone: Lessons from a Belfast writing centre. Arts and Humanities in Higher Education 10(1): 67-83. https://doi.org/10.1177/1474 $\underline{022210385276}$

Shore, C. 2010. Beyond the multiversity: Neoliberalism and the rise of the schizophrenic university. Social Anthropology 18(1): 15-29. https://doi.org/10.1111/j.1469-8676.2009.00094.x

Smit, R. 2012. Towards a clearer understanding of student disadvantage in higher education: Problematising deficit thinking. Higher Education Research \& Development 31(3): 369-380. https://doi.org/10.1080/07294360.2011.634383

Thesen, L. 2014. Risk as productive: Working with dilemmas in the writing of research. In L. Thesen and L. Cooper (eds.) Risk in academic writing: Postgraduate students, their teachers, and the making of knowledge. Bristol: Multilingual Matters. pp. 1-26. https://doi.org/10.21832/9781783091065-004

Volbrecht, T. and C. Boughey. 2004. Curriculum responsiveness from the margins? A reappraisal of academic development in South Africa. In H. Griesel (ed.) Curriculum responsiveness: Case studies in higher education. Pretoria: South African Universities ViceChancellors Association. pp. 57-80. 